\title{
Study and Optimization of Electric Heating for Oil and Petroleum Products Pipeline
}

\author{
Alexander Pavlov, Igor Plohov, Sergey Drozdov, Vadim Smirnov \\ Pskov State University, Faculty of Electric drive and automation systems, Address: Lenin Square 2, \\ Pskov, 180000, Russia
}

\begin{abstract}
The objectives of the study are to analyze the transients in heated pipelines using the finite element method and the achievement of reduction of energy losses during transportation of liquids in pipelines with electric heating systems by determining the optimal operating conditions and design parameters of the pipeline and electric heating system.
\end{abstract}

Keywords: polymer pipes, electric heating, experiment planning theory, finite element method (FEM), exponential regression model, the minimum energy criterion.

\section{INTRODUCTION}

During transportation of oil and petroleum products (hereinafter oil) through pipelines, a problem with cooling of the transported fluid by environment arises. Cooling fluid increases its viscosity, which causes an increase in hydraulic losses and adversely affect the pump stations. Besides, temperature decrease can lead to deposition of paraffin on the walls of the pipeline. Therefore, different types of heaters are widely used [1, 2]. Obvious advantages of electric heating systems (EHS) prior to similar water and steam systems are: small material consumption, easy installation, no corrosion processes and resistance to large temperature variations [3].

Flexible polymer pipes were developed at the beginning of the $80 \mathrm{~s}$ of the 20 century to prevent corrosion of pipeline transport. The basis of the flexible pipe engineering solutions were established by Russian and French oil experts, working in a joint project to create a method of drilling deep wells with a continuous process of tripping. This particular design of flexible drill pipes, which had been being tested for 5 years while drilling an experimental deep borehole, were put behind the foundation of pipe designs for the pipeline transport [4].

\section{MATERIALS AND METHODS}

The design of the polymer pipe

One of the disadvantages of flexible polymeric pipe designs with electric heating is uneven heating of the transported product inside the pipe and the difficulty of controlling the heating process in case of transient state (non-stationary behavior) [5]. Authors developed the design of polymer pipe, which provides uniform heating of the inner tube space filled by any agent.
Self-regulated heating elements (HE) provide even heating due to polymer allow with a positive temperature factor of resistance. HE consists of two longitudinal electrical conductors separated by a polymer alloy. The polymer alloy is uniformly distributed over the inner layer of the cylindrical tube. Longitudinal and transverse projections developed umbilical shown in Figure 1.

Our design consists of flexible polymer working tube over which there is a layer of a polymer alloy 2 within which longitudinally has two symmetrical diametrically opposed electrical conductors 3 and 4 . A layer of a polymer alloy 2 is covered with the shielding layer 5. On top of the shield layer 5 is laid insulating layer 6 (e.g., polyethylene foam), the surface of which formed the outer shell 7
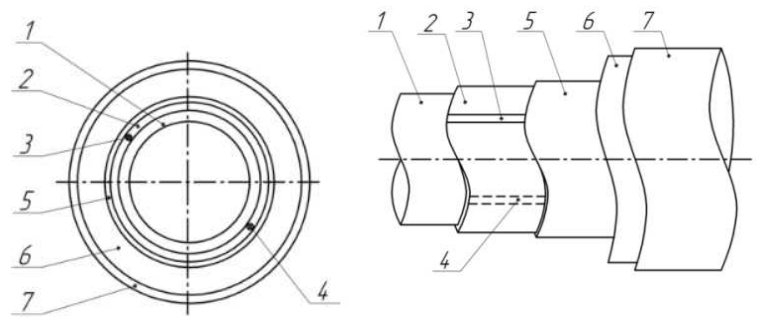

Fig. 1 - The design of the polymer tube with electrical heating

A layer of a polymer alloy 2 is a conductor of electric current, therefore currents appear over the entire length of a self-regulating cable between the electrical conductors 3 and 4 through a layer of a polymer alloy 2 . While the current flow the polymer alloy is heated, transferring the heat of fluid flowing in the pipeline, thus increasing the electrical resistance of a polymer alloy. At various sections of self-regulating heating layer, the heating capacity can be different depending on the temperature of the http://dx.doi.org/10.17770/etr2017vol3.2614 
polymer alloy. Thus, we achieve self-regulation of the heating power. As a result of the uniform distribution of the polymer alloy layer around the inner tube space, and due to the symmetric diametrically opposite location of conductors, we achieve uniform heat power output around the inner tube space and uniform input of heat in the forgoing space. Also due to the uniformly distributed heat resistance on the way of the heat flow from the polymer alloy layer to the inner tube space.

Selection of important factors

For the transitional process approximation, we analyzed pipelines design parameters, environmental conditions and characteristics of the ground. As a result, we highlighted factors that have an impact on the pipeline system operation of the electric heating

Table 1.

Factors and Ranges of Variation

\begin{tabular}{|c|c|c|c|c|}
\hline \multirow{2}{*}{ № } & \multirow{2}{*}{ Factor } & \multicolumn{2}{|c|}{$\begin{array}{l}\text { Ranges of } \\
\text { variation }\end{array}$} & \multirow{2}{*}{ 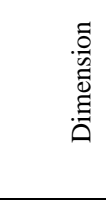 } \\
\hline & & $\begin{array}{ll}\overrightarrow{0} & \overline{0} \\
0 & 0 \\
0 & 0\end{array}$ & $\begin{array}{l}\overline{0} \\
\overline{2} \\
\bar{D}\end{array}$ & \\
\hline 1 & $\begin{array}{l}\text { Heat capacity of crude } \\
\text { oil }\end{array}$ & 1.7 & 2.1 & $\mathrm{~kJ} /(\mathrm{kg} \cdot \mathrm{s})$ \\
\hline 2 & Density of oil & 0.8 & 1 & $\mathrm{t} / \mathrm{m}^{3}$ \\
\hline 3 & $\begin{array}{l}\text { Heat capacity of } \\
\text { insulation }\end{array}$ & 1.5 & 2.4 & $\mathrm{~kJ} /(\mathrm{kg} \cdot \mathrm{s})$ \\
\hline 4 & $\begin{array}{l}\text { Thermal conductivity of } \\
\text { insulation }\end{array}$ & 0.02 & 0.05 & $\mathrm{~W} / \mathrm{m}^{2} \cdot \mathrm{s}$ \\
\hline 5 & Density of insulation & 40 & 100 & $\mathrm{~kg} / \mathrm{m}^{3}$ \\
\hline 6 & Heat capacity of the soil & 1.1 & 3.3 & $\mathrm{~kJ} /(\mathrm{kg} \cdot \mathrm{s})$ \\
\hline 7 & $\begin{array}{l}\text { Thermal conductivity of } \\
\text { soil }\end{array}$ & 0.4 & 2.1 & $\mathrm{~W} / \mathrm{m}^{2} \cdot \mathrm{s}$ \\
\hline 8 & Density of the soil & 1.6 & 2.2 & $\mathrm{t} / \mathrm{m}^{3}$ \\
\hline 9 & $\begin{array}{l}\text { Environment } \\
\text { temperature }\end{array}$ & -50 & 50 & ${ }^{\circ} \mathrm{C}$ \\
\hline 10 & Coefficient A & 0 & $\begin{array}{c}0.00 \\
2\end{array}$ & $\begin{array}{l}\text { relative } \\
\text { units }\end{array}$ \\
\hline 11 & Coefficient B & 0.3 & 1 & $\begin{array}{l}\text { relative } \\
\text { units }\end{array}$ \\
\hline 12 & Radius of the inner tube & 20 & 200 & $\mathrm{~mm}$ \\
\hline 14 & $\begin{array}{l}\text { Thermal conductivity of } \\
\text { crude oil }\end{array}$ & 0.1 & 0.2 & $\mathrm{~W} / \mathrm{m}^{2} \cdot \mathrm{s}$ \\
\hline 15 & $\begin{array}{l}\text { Temperature of crude } \\
\text { oil }\end{array}$ & -50 & 50 & ${ }^{\circ} \mathrm{C}$ \\
\hline 16 & $\begin{array}{l}\text { Volumetric flow of } \\
\text { crude oil }\end{array}$ & 30 & 250 & $\mathrm{~m}^{3} /$ day \\
\hline 17 & Initial pipe temperature & -50 & 50 & ${ }^{\circ} \mathrm{C}$ \\
\hline 18 & Length of pipe & 50 & 250 & $\mathrm{~m}$ \\
\hline
\end{tabular}

List factors and their variation ranges are shown in Table 1. Factors change range based on the tabular ranges of values of the materials, and soil environments, which may be used in the manufacture and operation of the pipelines. Justification of the choice of values of the coefficients $A$ and $B$ will be presented below. To test the effect of changing the value of each factor to the target amount (power consumption system) computer experiment was conducted in which each of the factors was varied on several levels. As the importance criterion, we assumed influence on the level of the target function, not exceeding 5\%. The magnitude of effect was evaluated by the value $\delta_{\mathrm{F}}$ relative system response factor for individual variation from the average value to the upper (lower) in percentage by the following expression:

$$
\delta_{F}=\frac{P_{k}^{i}-P_{k}^{A}}{P_{k}^{A}} \cdot 100,
$$

where: $P_{k}^{i}$ - the amount of power in the $i$-th experiment in $k$-th point in time; $P_{k}^{A}-$ the amount of power in the central experimental experience in $k$-th time.

Of above factors the system response higher than $5 \%$ was recorded for 7 out of 18 factors (Table 2).

Table 2.

\begin{tabular}{|c|c|c|c|c|c|c|}
\hline \multicolumn{7}{|c|}{ Significant Factors } \\
\hline \multirow{2}{*}{ № } & \multirow{2}{*}{ Factor } & \multirow{2}{*}{ 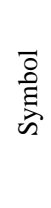 } & \multicolumn{2}{|c|}{$\begin{array}{l}\text { Ranges of } \\
\text { variation }\end{array}$} & \multirow{2}{*}{ 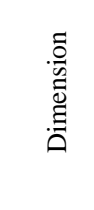 } & \multirow{2}{*}{$\begin{array}{c}\delta_{\Phi}, \\
\%\end{array}$} \\
\hline & & & $\begin{array}{ll}\overline{0} & 0 \\
3 & 0 \\
0 & 0\end{array}$ & 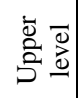 & & \\
\hline 1 & $\begin{array}{l}\text { Environment } \\
\text { temperature }\end{array}$ & $\mathrm{T}_{\mathrm{E}}$ & -60 & 20 & ${ }^{\circ} \mathrm{C}$ & 28,5 \\
\hline 2 & Coefficient A & A & $-0,6$ & $-0,3$ & $\begin{array}{l}\text { rel. } \\
\text { units }\end{array}$ & 6,8 \\
\hline 3 & Coefficient B & B & 10 & 60 & $\begin{array}{l}\text { rel. } \\
\text { units }\end{array}$ & 39,6 \\
\hline 4 & $\begin{array}{l}\text { Radius of the } \\
\text { inner tube }\end{array}$ & $\mathrm{R}$ & 10 & 70 & $\mathrm{~mm}$ & 25 \\
\hline 5 & $\begin{array}{l}\text { Temperature of } \\
\text { crude oil }\end{array}$ & $\mathrm{T}_{\mathrm{O}}$ & 2 & 38 & ${ }^{\circ} \mathrm{C}$ & 18,7 \\
\hline 6 & $\begin{array}{l}\text { Volumetric } \\
\text { flow of crude } \\
\text { oil }\end{array}$ & Q & 5 & 95 & $\mathrm{~m}^{3} /$ day & 16,2 \\
\hline 7 & Length of pipe & $\mathrm{L}$ & 50 & 250 & $\mathrm{~m}$ & 41,8 \\
\hline
\end{tabular}

$\mathrm{A}$ and $\mathrm{B}$ coefficients are calculated using the heating power variation graphs $\mathrm{P}(\mathrm{T})$. These relationships are included by manufacturers of selfregulating materials and confirmed by company "SST" through the testing (Figure 2). [6] 
Dependence of power density on the EHS temperature represented a linear function with the coefficients A and B:

$$
P(T)=A \cdot T+B
$$

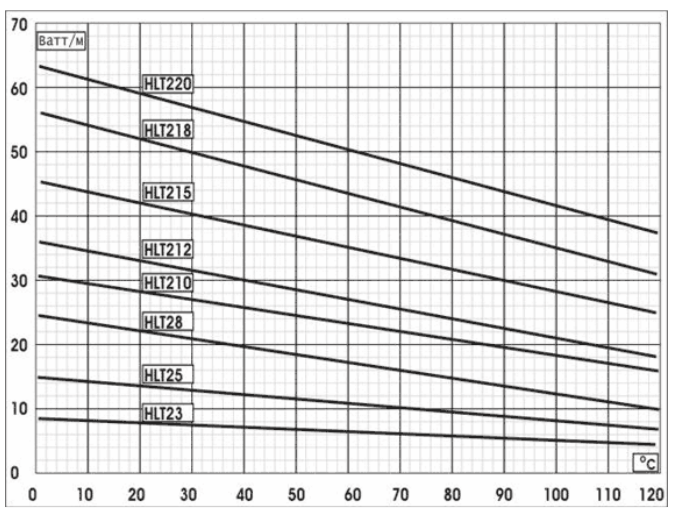

Fig. 2 - Heating power variation graphs $\mathrm{P}(\mathrm{T})$

According to preliminary computational and natural experiments, we found nonlinearity in the dependence of power consumption on certain factors and justified the exponential nature of transients in EHS.

Selecting dynamic model

A dynamic model of power consumption, describing the time behavior of the system for fixed values of the factors is

$$
P\left(C_{0}, C_{1}, C_{2}, \mathrm{t}\right)=C_{0} \cdot e^{\left(C_{1} \cdot t\right)}+C_{2},
$$

where coefficients $C_{0}, C_{1}, C_{2}$ are functions of the form

$$
C_{m}\left(X_{0}, X_{1}, . . X_{j} . ., X_{K}\right)
$$

where: $X_{j}$ - the value of the $j$-th factor; $m=0,1,2-$ number of the coefficient $\mathrm{C} ; K$ - number of important factors.

In this regard, as the static mathematical model chosen incomplete quadratic regression

$$
C_{m}\left(X_{0} . . X_{K}\right)=b_{0}^{C_{m}}+\sum_{j=1}^{K} b_{j}^{C_{m}} X_{j}+\sum_{j=1}^{K} b_{j j}^{C_{m}} X_{j}{ }^{2}
$$

where: $b_{0}^{C_{m}}, b_{j}^{C_{m}}, b_{j j}^{C_{m}}$ - calculated coefficients of a mathematical model.

Orthogonal central composite plan

Orthogonal central composite plan (OCCP) was selected as an experiment plan. Parameter values of OCCP:

- number of factors $-N=7$;

- fractionality $-p=4$;

- number of tests in core plan $-N_{Я}=2^{(N-p)}=8$;

- number of star points $-N_{a}=2 N=14$;
- number of experiments in the middle of the plan $-N_{0}=1$;

- total number of tests $-N=N_{A}+N_{a}+N_{0}=23$;

- star shoulder $-\alpha=\sqrt{2^{\frac{N-p}{2}-1}\left(\sqrt{N}-2^{\frac{N-p}{2}}\right)}=1,668$.

Modeling the pipeline heating process with electric heating was performed in COMSOL Multiphysics 4.4 [7, 8]. We modeled the transition process in the heated pipeline, namely, the inclusion of an EHS simultaneously with the start of the transport of the product through the pipe. Construction of the model is made in the module for the calculation of non-isothermal flow of liquids in pipelines (Non-isothermal Pipe Flow interface) [9]. Machining simulation results produced in MathCad 15.

Exponential transients obtained at different combinations of factors and approximated by the formula (5). The approximation was carried out by the method of least squares. We minimize the objective function. The objective function is the sum of squared residuals of the experimental $\left(h^{\langle i\rangle}\right)_{k}$ and theoretical exponent $C_{0} \cdot e^{\left(C_{1} \cdot t_{k}\right)}+C_{2}$ for each combination of the plan of factors:

$$
Q\left(C_{0}, C_{1}, C_{2}\right)=\sum_{k=0}^{N_{t}}\left[C_{0} \cdot e^{\left(C_{1} \cdot t_{k}\right)}+C_{2}-\left(h^{\langle i\rangle}\right)_{k}\right]^{2} \rightarrow \min ,(6)
$$

where $N_{t}=100$ - number of control points in each of the experiments; $\left(h^{\langle i\rangle}\right)_{k}$ - experimental value of magnitude in the $k$-th point in time $i$-th experiment.

The accuracy of selection coefficients estimated by relative approximation mistake

$\varepsilon=\frac{100}{N_{r}} \sum_{k=0}^{N_{t}} \frac{\left|C_{0} \cdot e^{\left(C_{1} \cdot t\right)}+C_{2}-\left(h^{\langle i\rangle}\right)_{k}\right|}{\left(h^{\langle i\rangle}\right)_{k}}$,

where: $N_{r}$ - number of experiments.

Verification received mathematical model adequacy revealed that high precision (less than 5\%) is achieved in the combinations of factors to those shown in close OCCP, otherwise the relative approximation mistake (7) may extend beyond the accepted limits of $15 \%$.

Using OCCP was obtained by approximating an additional function of the form

$T_{K}=b_{0}^{T_{k}}+\sum_{i=1}^{K} b_{i}^{T_{k}} X_{i}+\sum_{i=1}^{K} b_{i i}^{T_{k}} X_{i}^{2}$

where: $T_{K}-$ the average temperature of the oil in the final section of the pipeline.

The relative mistake of approximation $\varepsilon(7)$ was $3.27 \%$. 


\section{Heuristic plan}

We developed a new unsaturated heuristic plan, including pairwise interactions between factors, to improve the accuracy of approximation. The objective function over time has previous form (3).To determine the level of influence of individual factors on the values of the coefficients of the regression $C_{0}, C_{1}, C_{2}$ used equation of the form

$$
\mathrm{C}_{m}\left(X_{1} . . X_{K}\right)=b_{0}^{\mathrm{C}_{m}}+\sum_{j=1}^{K} X_{j} \cdot b_{1, j}^{\mathrm{C}_{m}}+\sum_{j=1}^{K} X_{j}^{2} \cdot b_{2, j}^{\mathrm{C}_{m}}+\sum_{j=1}^{K} X_{j}^{3} \cdot b_{3, j}^{\mathrm{C}_{m}}(9)
$$

where: $m=0,1,2-$ number of coefficient $\mathrm{C} ; j-$ number of factor $(1 . .7) ; \mathrm{C}_{m}\left(X_{1} . . X_{K}\right)-$ value of $m$-th coefficient to a combination of factors $\left(X_{1} . . X_{K}\right) ; K-$ number of factors; $b_{0}^{\mathrm{C}_{m}}, b_{1, j}^{\mathrm{C}_{m}}, b_{2, j}^{\mathrm{C}_{m}}, b_{3, j}^{\mathrm{C}_{m}}-$ the calculated coefficients of the factors $X$ first, second and third order, respectively. After a series of trial calculations to improve the accuracy of the regression equations were added to the terms describing the pair interaction of factors:

$$
\begin{gathered}
\mathrm{C}_{m}\left(X_{1} . . X_{K}\right)=b_{0}^{\mathrm{C}_{m}}+\sum_{j=1}^{K} X_{j} \cdot b_{1, j}^{\mathrm{C}_{m}}+\sum_{j=1}^{K} X_{j}^{2} \cdot b_{2, j}^{\mathrm{C}_{m}}+ \\
\sum_{j=1}^{K} X_{j}^{3} \cdot b_{3, j}^{\mathrm{C}_{m}}+\sum_{q \neq p}^{K} b_{q, p}^{\mathrm{C}_{m}} \cdot X_{q} \cdot X_{p} \\
P\left(C_{0}, C_{1}, C_{2}, \mathrm{t}\right)=C_{0} \cdot e^{\left(C_{1} \cdot t\right)}+C_{2},
\end{gathered}
$$

where $b_{q, p}^{\mathrm{C}_{m}}-$ coefficients of pair interactions of factors.

The objective function, which is subjected to minimize in order to determine the optimal values of coefficients has the form:

$$
\begin{array}{r}
Q_{\mathrm{C}_{m}}\left(b_{0}^{C_{m}}, b_{1, j}^{C_{m}}, b_{2, j}^{C_{m}}, b_{3, j}^{C_{m}}, b_{\mathrm{q}, \mathrm{p}}^{C_{m}}\right)= \\
\sum_{i=0}^{N m}\left[\mathrm{C}_{m}\left(X_{1, i} . X_{K, i}\right)-\mathrm{C}_{m}^{\Lambda}\left(X_{1, i}^{\Lambda} . X_{K, i}^{\Lambda}\right)\right]^{2} \rightarrow \text { min }
\end{array}
$$

where: $N m-$ number of heuristic plan tests; $i-$ number of test; $\mathrm{C}_{m}\left(X_{1, i} . . X_{K, i}\right)-m$-th coefficient, obtained by the regression formula for the combination of factors $\left(X_{1, i} . . X_{K, i}\right) ; \hat{C}_{m}\left(\Lambda_{1, i}^{\Lambda} . . X_{K, i}\right)-m$ th coefficient obtained by the distributed model in Comsol Multiphysics for combination of factors $\left({ }^{\wedge}{ }_{1, i} . . X_{K, i}^{\Lambda}\right)$.

We define a mathematical expression for the relative mean mistake of approximation of experimental data by a polynomial regression. Residual function is quasi random variable

$$
O_{i}=\left|\mathrm{C}_{m}\left(X_{1, i} . . X_{K, i}\right)-\mathrm{C}_{m}^{\Lambda}\left(X_{1, i}^{\Lambda} . . X_{K, i}^{\Lambda}\right)\right|
$$

To determine the relative mistake, we need to find the middle line graphs of two functions:

$$
L_{A V i}=\frac{1}{2}\left|\mathrm{C}_{m}\left(X_{1, i} . . X_{K, i}\right)+\stackrel{\Lambda}{\mathrm{C}}_{m}\left(\Lambda_{1, i}^{\Lambda} . . X_{K, i}^{\Lambda}\right)\right| .
$$

The relative mistake for the $i$-th experience and averaged mistake experimentation through $\mathrm{Nm}$ respectively:

$$
\begin{gathered}
\delta O_{j}=\frac{O_{j}}{L_{A V j}}, \\
\delta_{A V}=\frac{\sum_{i=0}^{N m} \delta O_{j}}{N m}=\frac{2}{N m} \sum_{i=0}^{N m} \frac{\left|\mathrm{C}_{m}\left(X_{1, i} . . X_{K, i}\right)-\mathrm{C}_{m}\left(X_{1, i}^{\Lambda} . X_{K, i}^{\Lambda}\right)\right|}{\left|\mathrm{C}_{m}\left(X_{1, i} . . X_{K, i}\right)+\mathrm{C}_{m}\left(X_{1, i}^{\Lambda} . . X_{K, i}^{\Lambda}\right)\right|}
\end{gathered}
$$

Results of calculating residual values and mistakes of functions are shown in Table 3. In order to smooth the results of $C_{1}$ introduced logarithm. For the $C_{0}$ and $C_{2}$, the average error is less than $5 \%$. The accuracy of $C_{1}$ does not exceed $15 \%$ of that for the multivariate approximation is acceptable.

Table 3.

Approximation Mistakes of the Mathematical Model

\begin{tabular}{|l|l|l|l|l|}
\hline № & \multicolumn{1}{|c|}{ Parameter } & $\mathrm{C}_{0}$ & $\mathrm{Ln}\left(\mathrm{C}_{1}\right)$ & $\mathrm{C}_{2}$ \\
\hline 1 & $\begin{array}{l}\text { Arithmetic average of the residual } \\
\text { functions }\end{array}$ & 0.12 & 0.0064 & 0.1 \\
\hline 2 & Average mistake, \% & 4.81 & 14.394 & 4.8 \\
\hline
\end{tabular}

To assess the adequacy of the obtained expressions, authors conducted computational experiments with arbitrary values of a combination of factors (the variation within the test range) by substituting the values of the coefficients $b$, and calculate the average approximation mistake. According to results of computational experiments, standard mistake does not exceed the permissible values (Table 3).

The energy consumption of EHS is determined by integrating (11) over a time period $\tau$ :

$$
W_{H}=\int_{0}^{\tau} P\left(C_{0}, C_{1}, C_{2}, \mathrm{t}\right) d t=\int_{0}^{\tau}\left(C_{0} \cdot e^{\left(C_{1} \cdot t\right)}+C_{2}\right) d t=\frac{C_{0} \cdot\left(e^{\left(C_{1} \cdot \tau\right)}-1\right)}{C_{1}}+C_{2} \tau
$$

\section{Exponentially-regression model}

Thus, the final appearance of the combined exponentially regression model represented by expressions (9), (10) and (17) with the calculated coefficients $b_{0}^{C_{m}}, b_{1, j}^{C_{m}}, b_{2, j}^{C_{m}}, b_{3, j}^{C_{m}}, b_{q, p}^{C_{m}}$.

A study of the properties of the pipe with a selfregulating EHS using the constructed model and the 
Environment. Technology. Resources, Rezekne, Latvia Proceedings of the $11^{\text {th }}$ International Scientific and Practical Conference. Volume III, 242-248

technique of optimization by the criterion of minimum power consumption, taking into account transients.

Optimization of the parameters of the mathematical model

Optimization of the parameters is carried out by the criterion of minimum energy costs for transportation and heating oil. Energy costs for heating is counted as passing heating costs and costs for preheating, if it is technically necessary. For example, in the case of high-viscosity oil transported that require additional measures to prevent paraffin precipitation and other forms of precipitation. Furthermore, the use of preheating in some cases, allows the use of heating pipeline system associated only to stabilize the temperature of the transported fluid. The criterion of minimum total cost of transportation and heating is:

$$
W_{M}+W_{H}+W_{T} \rightarrow \min ,
$$

where: $W_{M}-$ energy $[\mathrm{J}]$, spent on the work of pumping equipment; $W_{H}$ - energy spent on passing an electric heating oil in the pipeline; $W_{T}$ - energy spent on preheating the oil.

Optimization of the pipeline parameters is carried out under specified conditions: a certain temperature, the soil, the specified bandwidth, the known properties of the oil, etc. During operating, many pipeline conditions are changing. Thermal operation mode of the pipelines is unsteady for many reasons [10]: seasonal changes in soil temperature, variations pipeline capacity, emergency stop pumping. With increasing heating temperature, energy consumption of the pre-heating system increases; energy consumption of associated heating system, oil viscosity, the pressure loss in the pipe and the cost of pumping oil reduced (Figure 3 ).

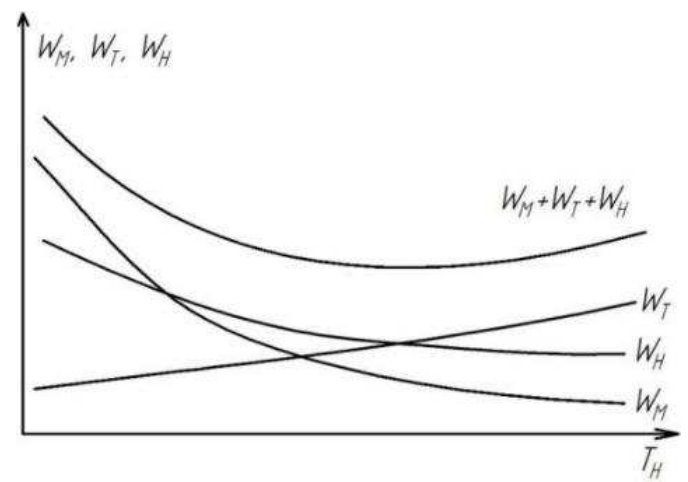

Fig. 3 - The dependence of the energy consumption on the oil temperature

Oil temperature $T_{H}$ are accepted in view of technological limitations. In particular, for highviscosity oils in the oil temperature of the end portion should be at least 3-5 degrees higher than its solidification temperature.
Power consumed by the pump per unit in time:

$$
P_{M}=\frac{Q H \rho_{H} g}{\eta_{M}},
$$

where: Q - volumetric oil flow rate, $\mathrm{m}^{3} / \mathrm{s}$; $H=\frac{\lambda L V^{2}}{2 d_{B H} g}$,

$H$ - head loss in the pipeline, $\mathrm{m}$; $\rho_{H}=\rho_{293}-\left(1.825-0.001315 \rho_{293}\right) \cdot(\mathrm{Tn}-293) \quad-$ density of oil, $\mathrm{kg} / \mathrm{m}^{3} ; \rho_{293}-$ density of oil at $20^{\circ} \mathrm{C}$, $\mathrm{kg} / \mathrm{m}^{3} ; \eta_{M}-$ coefficient of efficiency of the pump, $\lambda$ - kinematic coefficient of friction; $L$ - pipeline length, $\mathrm{m} ; V-$ oil flow rate, $\mathrm{m} / \mathrm{s} ; d_{B H}-$ inner diameter of pipeline, $\mathrm{m}$.

The energy consumed by the pump for a period in time $\tau$

$$
W_{M}=P_{M} \tau
$$

The power consumed by the pre-heating system of oil:

$$
P_{T}=\frac{Q \rho_{H} c_{P}\left(T_{S}-T_{S . C O}\right)}{\eta_{T}}
$$

where: $c_{P}$ - specific heat of crude oil, $\mathrm{J} /(\mathrm{kg} \cdot \mathrm{K})$; $T_{S . C O}$-crude oil temperature coming from the borehole, $\mathrm{K} ; \eta_{T}$ - coefficient of efficiency of pre-heat system.

The energy consumed by the pre-heating system in time $\tau$

$$
W_{T}=P_{T} \tau
$$

We integrate the mathematical expression for the power of associated heating system $P\left(t, Q, R, A, B, T_{O}, T_{E}, L\right)$ in time and get an expression that describes the amount of energy consumed electric heating system associated for the period $\tau$

$$
W_{T}\left(Q, R, A, B, T_{O}, T_{E}, L\right)=\int_{0}^{\tau} P\left(t, Q, R, A, B, T_{O}, T_{E}, L\right)
$$

The total energy consumption described by systems $W=W_{M}+W_{H}+W_{T}$, taking into account important factors in the expressions for the individual energy subsystems

$$
\begin{array}{r}
W\left(Q, R, A, B, T_{O}, T_{E}, L\right)=W_{M}\left(Q, R, T_{O}, L\right)+ \\
W_{T}\left(Q, T_{O}\right)++W_{H}\left(Q, R, A, B, T_{O}, T_{E}, L\right)
\end{array}
$$




\section{RESULTS AND DISCUSSION}

With (23), we assess the value of consumed energy and the optimization of the parameters (important factors) in order to minimize energy consumption.

We analyzed influence of factors on the value of the total consumed energy. These curves were obtained for the following combinations of values of factors corresponding to the central test heuristic unsaturated plan using hybrid-exponential regression mathematical model.

- Volumetric flow of crude oil: $Q=50, \mathrm{~m}^{3} /$ day;

- Inner radius of the pipeline: $R=0.04, \mathrm{~m}$;

- Coefficient $A=-0.45$;

- Coefficient $B=35$;

- Temperature of the crude oil, flowing into the pipeline $T_{O}=20,{ }^{\circ} \mathrm{C}$;

- Environment temperature $T_{E}=-20,{ }^{\circ} \mathrm{C}$;

- Pipeline length $L=150, \mathrm{~m}$.

Graphic dependences for volumetric flow of oil and oil temperature are shown in Figure 4.

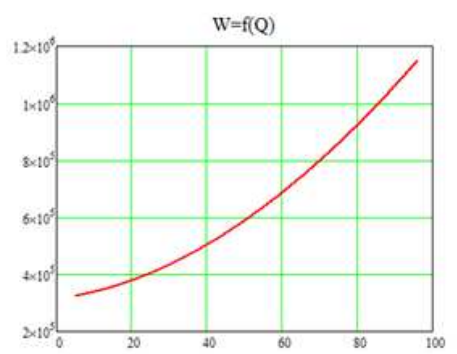

Volumetric flow, $\mathrm{m}^{3} /$ day

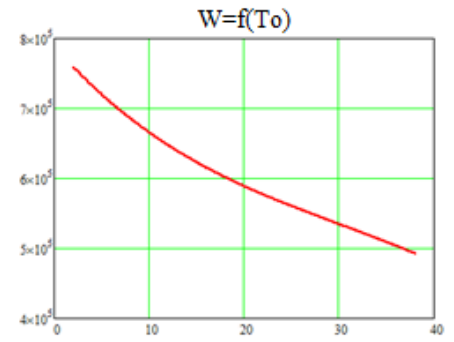

Oil temperature, ${ }^{\circ} \mathrm{C}$

a)

b)

Fig. 4 - Dependences of the of consumed energy by factors: a) changing the crude oil flow rate in the pipeline;

b) changing the inlet crude oil temperature at the pipeline.

Subsystems energy costs individually and generally are reflected in Figure 5.

With increasing the crude oil temperature, coming into the pipeline after the pre-heating system, there is a decrease of amount of energy consumed by preheating subsystem, and decrease of costs for pumping oil. Growth of energy consumption is observed only for preheating subsystem. These results correspond to the theoretical dependencies. Based on the graph (Figure 5) that the heating oil temperature rise in the pipeline, leads to a decrease of the total energy consumed by system.

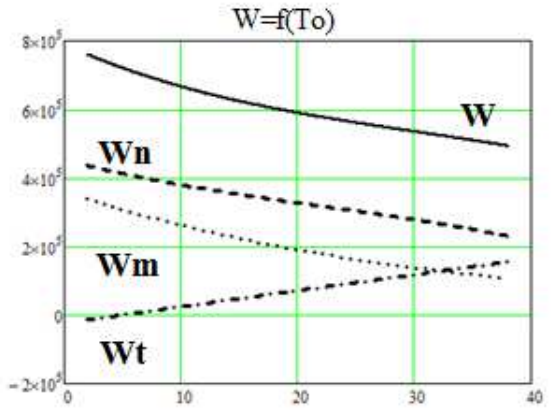

Fig. 5 - Energy costs

Determination of the oil temperature at the end of the pipeline

The oil temperature in the final section of the pipeline:

$T_{K} \geq b_{0}^{T_{k}}+\sum_{i=1}^{n} b_{i}^{T_{k}} X_{i}+\sum_{i=1}^{n} b_{i i}^{T_{k}} X_{i}^{2}$

$T_{K}$ set as the desired value (a number) or in the form of expression $T_{K}=T_{H E A T}+\Delta T$, where $\Delta T-$ excess oil temperature in the final section of the pipeline to the temperature of the oil at the inlet of pipeline, ${ }^{\circ} \mathrm{C}$.

As environmental temperature, $T_{E}$ chosen average temperature in the ground for the operation period of the pipeline.

Algorithm of optimization by the criterion of a minimum energy consumption

1. To identify the number of fixed, unchanging parameters and duration of the process (the upper limit of time integration).

2. To select the range of variation of the values of the factors are optimized. These ranges are based on a previously selected for the mathematical model ranges (within the ranges of the mathematical model is adequate) and based on the technological and constructive restrictions;

3. To identify boundary conditions and to determine minimum acceptable final oil temperature $\mathrm{T}_{\mathrm{K}}$.

4. To conduct minimization of the objective function;

5. To substitute these optimized factors values in expression (23). If necessary, compare optimized energy consumed with the original value.

\section{CONCLUSIONS}

1. We developed three-dimensional computer simulation distributed mathematical model of polymer pipeline with a self-regulating EHS. The model is created in Comsol Multiphysics using the FEM. We selected a list of parameters that have a significant influence on the course of the transition process. With the application of the experiment planning theory authors constructed 
Environment. Technology. Resources, Rezekne, Latvia Proceedings of the $11^{\text {th }}$ International Scientific and Practical Conference. Volume III, 242-248

an orthogonal central composite plan, calculated by the constant coefficients of the regression model for the power transition process. The regression model for the temperature in the final section of pipeline with EHS also developed.

2. Authors developed experimental plan, taking into account the pairwise interactions between significant factors of the mathematical expression of the power transition process and hybrid heuristic mathematical model (exponential regression) of the transition process, describing the dynamics of self-regulated pipeline with electric heating.

3. Authors obtained expression of the total energy consumed by the pump and heating subsystems, in view of relevant factors included in the expression for the energy of the individual subsystems, and power graphics for electric heating systems and pump energy consumption and guidelines for choosing the optimal oil heating temperature.

4. We developed method for optimization of pipeline construction parameters of the selfregulatory system with electric heating according to criterion of minimum energy.

\section{REFERENCES}

[1] Strupinskiy M.L. «Classification and main characteristics of the low temperature electrical heating system for the large area objects», Вестник МЭИ. - 2010. - № 3. С. 90-99.

[2] Farago, P.S. «An Introduction to Linear Network», The English Universities Press Ltd. - 1961. PP. 117-121.

[3] Быков, И.Ю. «Композицонно - волокнистые трубы в нефтегазовом комплексе», под редакцией доктора технических наук, профессора И.Ю. Быкова - М: Изд. ЦентрЛитНефтеГаз. - 2008. - 271 с.

[4] Реммаш-сервис: Гибкие трубы, режим доступа [Online]. Available: http://remmash63.ru/2.html. (Accessed: 12.05.2014)

[5] «Саморегулируемый кабель для выкидных трубопроводов», utility patent № RU 142154 U1, Authors: Плохов И.В., Павлов А.Б. Patent owner: ООО НИП «Дельта-Т». Published. 26.06.2014.

[6] Хренков, Н.Н. «Расчет режимов остывания и разогрева трубопроводов с учетом замерзания и плавления». Промышленный электрообогрев и электроотопление. 2011. - №3. - C. 18-22.

[7] The COMSOL Multiphysics User's Guide [Online], Available: https://www.comsol.com/.

[8] S.E. Haaland, «Simple and Explicit Formulas for the Friction Factor in Turbulent Flow», J. Fluids Engineering (ASME). - 1983. - vol. 103. - №5. - PP. 89-90.

[9] Heat Transfer Module User's Guide [Online]. Available: https://www.comsol.com/.

[10] Гаррис, Н.А. «Расчет эксплуатационных режимов магистральных неизотермических нефтепродуктопроводов с применением динамических характеристик», Нефтегазовое дело. - 2003. - №2. - 8 с. 